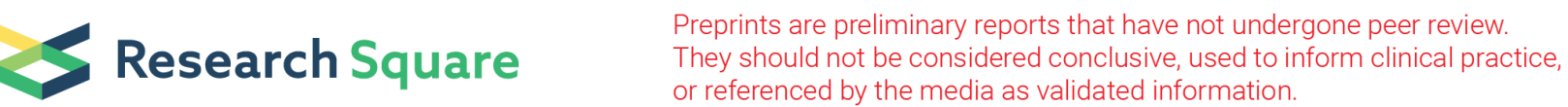

\section{Transcriptome Analysis of Aedes Albopictus Midguts Infected by Dengue Virus Identifies a Gene Network Module Highly Associated with Temperature}

\section{Zhuanzhuan Liu}

Xuzhou Medical University

YeXu

Southern Medical University

Yudi Li

Xuzhou Medical University

Shihong Xu

Xuzhou Medical University

Yiji Li

Hainan Medical University

Ling Xiao

Taiyuan City Central Hospital

\section{Xiaoguang Chen}

Southern Medical University

\section{Cheng He}

Xuzhou Medical University

Kui-Yang Zheng ( $\nabla$ zky@xzhmu.edu.cn )

Xuzhou Medical University

\section{Research Article}

Keywords: Aedes albopictus, dengue virus-2, temperature, RNA sequencing, gene correlation network analysis

Posted Date: January 18th, 2022

DOI: https://doi.org/10.21203/rs.3.rs-1256526/v1

License: (c) (1) This work is licensed under a Creative Commons Attribution 4.0 International License. Read Full License 


\section{Abstract}

Background: Dengue is prevalent worldwide and transmitted by Aedes mosquitoes. Temperature is a strong driver of dengue transmission. However, little is known about the underlying mechanisms.

Methods: Aedes albopictus mosquitoes exposed or not to dengue virus (DENV)-2 were reared at $23^{\circ} \mathrm{C}$, $28^{\circ} \mathrm{C}$ and $32^{\circ} \mathrm{C}$, and midguts and residual tissues were evaluated at 7 days after infection. RNA sequencing of midgut "pools" from the control group (CT), midgut breakthrough group (MB) and midgut nonbreakthrough group (MNB) at different temperatures was performed. The transcriptomic profiles were analyzed using the R package, followed by weighted gene correlation network analysis (WGCNA) and KEGG analysis to identify the important molecular mechanisms regulated by temperature.

Results: The midgut infection rate (MIR) and midgut breakthrough rate (MBR) at $28^{\circ} \mathrm{C}$ and $32^{\circ} \mathrm{C}$ were significantly higher than those at $23^{\circ} \mathrm{C}$, which indicates that high temperature facilitates DENV-2 breakthrough in the Ae. albopictus midgut. Transcriptome sequencing was performed to investigate the antiviral mechanism in the midgut. The results show that the midgut gene expression datasets clustered regarding temperature, blood feeding and midgut breakthrough. Over 1500 differentially expressed genes (DEGs) were identified by pairwise comparisons of midguts at different temperatures. To assess key molecules regulated by temperature, we used WGCNA to identify 28 modules of co-expressed genes, and the ME3 module correlated with temperature. KEGG analysis indicates that RNA degradation, Toll and IMD signaling and other pathways are regulated by temperature.

Conclusions: Temperature affects the infection and breakthrough of Ae. albopictus midguts invaded by DENV-2, and Ae. albopictus midgut transcriptomes change with temperature. The candidate genes and key pathways regulated by temperature provide targets for the prevention and control of dengue.

\section{Background}

Dengue fever is an arthropod-borne disease caused by the dengue virus (DENV) [1]. In general, clinical manifestations vary after infection with DENV. The most people are asymptomatic or have only minor symptoms, including fever, rash, and body pain. However, a proportion of patients develop severe dengue, which manifests as severe bleeding, shock, and even death [2]. Although dengue is epidemic worldwide, it is mainly distributed in tropical and subtropical regions. It is estimated that approximately 400 million people are infected with DENV globally every year, with $25 \%$ of the population presenting clinical symptoms [3]. In recent years, dengue outbreaks have appeared in the Americas, Bangladesh, the Philippines, and Nepal [4-7]. In China, dengue frequently occurs in Guangdong, Guangxi, and Yunnan provinces. In 2014, the largest outbreak was reported in Guangdong Province, with 47056 cases and 6 deaths $[8,9]$. The epidemic area of dengue is constantly expanding, and the number of people at risk increases yearly.

Dengue is transmitted by mosquitoes of the genus Aedes, such as Aedes aegyptiand Aedes albopictus. Ae. aegypti is internationally recognized as the principal vector of dengue; Ae. albopictus is the secondary 
vector [10]. In China, the distribution of $A$ e. aegypti is limited to only a few areas of Guangdong, Hainan and Yunnan, and Ae. albopictus is the dominant mosquito species that causes dengue outbreaks in China; Ae. albopictus is distributed in perennial warm provinces and the north, southwest and southeast coastal areas [11]. Moreover, the geographical distribution of Ae. albopictus is continuing to expand with the acceleration of global warming, urbanization and trade, with an increased risk of dengue spread.

Temperature affects the prevalence of dengue $[12,13]$, and in the absence of measures to mitigate climate change, an additional 7.5 million dengue cases per year can occur. If the increase in temperature is maintained within $2^{\circ} \mathrm{C}$, the annual increase in dengue cases can be reduced by 1 to 3 million; if it is controlled within $1.5^{\circ} \mathrm{C}$, the number of cases will be further reduced [14]. In general, the risk of dengue increases with temperature change, which is primarily associated with improving the vector competence of mosquitoes to transmit DENV. In one study, when the temperature was higher than $26^{\circ} \mathrm{C}$, the extrinsic incubation period (EIP) of DENV in Ae. aegypti was approximately 1 week, but the EIP was prolonged when the temperature was lower than $21^{\circ} \mathrm{C}$; if the temperature was lower than $18^{\circ} \mathrm{C}$, Ae. aegypti could not transmit DENV [15]. Similar results were obtained for Aedes albopictus [16]. Nevertheless, the mechanism by which temperature affects the transmission of DENV by Aedes remains unclear.

Mosquito-borne viruses must overcome the mosquito's midgut and salivary gland barrier to replicate in mosquitoes; indeed, the midgut is the first barrier against a virus. Thus, the balance of the midgut environment affects the virus replication $[17,18]$. For example, in Ae. aegypti infected with Zika virus (ZIKV) and cultured at $20^{\circ} \mathrm{C}, 28^{\circ} \mathrm{C}$, and $36^{\circ} \mathrm{C}$, the gene expression profiles of the midgut changed with temperature, especially under low-temperature conditions $\left(20^{\circ} \mathrm{C}\right)$, which shows significant alterations in gene expression related to blood digestion, active oxygen metabolism and innate immunity [19].

Our previous research showed that DENV-2 was confined to the midgut of Ae. albopictus and slowly proliferated at $18^{\circ} \mathrm{C}$; when the temperature was $23-32^{\circ} \mathrm{C}$, DENV-2 broke through the midgut barrier of $A e$. albopictus and invaded the salivary glands [16]. To better understand the interaction between $A e$. albopictus and DENV-2 under different temperatures, the infection status in the midgut and remaining tissues of Ae. albopictus at $23^{\circ} \mathrm{C}, 28^{\circ} \mathrm{C}$ and $32^{\circ} \mathrm{C}$ was investigated. Transcriptome sequences proceeded from the midgut of $A e$. albopictus. In addition, gene network modules highly related to temperature were identified using a weighted gene correlation network analysis (WGCNA).

\section{Methods}

\section{Mosquitoes}

Ae. albopictus was collected in Foshan City, Guangdong Province, China, and bred in a standardized room (constant $27 \pm 1^{\circ} \mathrm{C}, 70-80 \%$ relative humidity and a $16 \mathrm{~h}: 8 \mathrm{~h}$ light-dark photoperiod). The eggs hatched into larvae in dechlorinated water, and the larvae were fed turtle food until the pupal stage. The pupae were transferred into a cup and placed in a mosquito cage. Adults emerged during 2-3 $d$ and were fed $10 \%$ glucose. The mosquitoes were fed defibrinated sheep blood for egg production. 


\section{The proliferation of dengue virus}

Experimental operation of DENV-2 was performed in a biological safety cabinet. DENV-2 (New Guinea C) proliferated in C6/36 cells. C6/36 cells cultured in RPMI- 1640 medium containing $10 \%$ fetal bovine serum (FBS) were inoculated with DENV-2 at a multiplicity of infection (MOI) of 1 ; the culture flask was gently shaken for $15 \mathrm{~min}$ at room temperature and subsequently incubated at $37^{\circ} \mathrm{C}$ and $5 \% \mathrm{CO}_{2}$ for 2 days. The supernatant was harvested after centrifugation at $1500 \times \mathrm{g}$ for $5 \mathrm{~min}$. The DENV-2 titer was determined based on the $50 \%$ tissue culture infective dose $\left(\operatorname{TCID}_{50}\right)[20]$.

\section{Mosquito infection with DENV-2}

The mosquito infection experiment was performed in a biosafety secondary laboratory (BSL-2). Five- to 7day-old female Ae. albopictus mosquitoes were starved for 16-20 h. Fresh DENV-2 (8.625 $\log _{10} \mathrm{TCID}_{50} / \mathrm{mL}$ ) was mixed with defibrinated sheep blood at a ratio of $2: 1$. After incubating at $37^{\circ} \mathrm{C}$ for $30 \mathrm{~min}$, the blood meal was transferred into a Hemotek blood reservoir unit (Discovery Workshops, Lancashire, UK). Ae. albopictus mosquitoes were allowed to feed on the blood meal for $30 \mathrm{~min}$. The engorged mosquitoes were anesthetized with $\mathrm{CO}_{2}$, placed in $250 \mathrm{~mL}$ paper cups covered with gauze (10 mosquitoes/cup), and maintained in different incubators precisely set at $23^{\circ} \mathrm{C}, 28^{\circ} \mathrm{C}$ and $32^{\circ} \mathrm{C}, 80 \%$ relative humidity and a $16 \mathrm{~h}: 8 \mathrm{~h}$ (light:dark) photoperiod. For the control group, DENV-2 was replaced with RPMI-1640/2\% FBS. All mosquitoes were fed $10 \%$ glucose solution.

\section{DENV-2 detection}

The midgut and residual tissues of each mosquito were dissected and independently detected at 7 days postinfection (dpi). Total RNA was extracted according to the manufacturer's protocol. cDNA was synthesized using $4 \mu \mathrm{L}$ RNA and random primers following the recommendations of the GoScript ${ }^{\text {TM }}$ Reverse Transcription System (Promega, Madison, WI, USA). DENV-2 positivity was determined by polymerase chain reaction (PCR) using the previously described primers (forward primer: 5 '-

TCAATATGCTGAAACGCGCGAGAAACCG-3'; reverse primer: 5'-TTGCACCAACAGTCAATGTCTTCAGGTTC$3^{\prime}$ )[21]. PCR was performed according to the protocol of Maxima Hot Start Green PCR Master Mix (Thermo Fisher Scientific Inc., Waltham, MA, USA). The 511-bp target fragment was identified by $1 \%$ agarose gel electrophoresis. The residual RNA was stored at $-80^{\circ} \mathrm{C}$.

Determination of the midgut infection, midgut breakthrough and midgut nonbreakthrough rates of Ae. albopictus

If DENV-2 was simultaneously detected in the midgut and the residual tissue of Ae. albopictus, it was considered that DENV-2 had broken through the midgut barrier of the mosquitoes and constituted the midgut breakthrough group (MB). If DENV-2 was detected only in the midgut and not in residual tissue, it was considered that the virus had not broken through the midgut barrier, which was termed the midgut nonbreakthrough group (MNB). The midgut infection rate (MIR), midgut breakthrough rate (MBR), and midgut nonbreakthrough rate (MNBR) of Ae. albopictus were determined using the following formulas. 
MIR =number of positive midguts/total number of midguts tested $\times 100 \%$

MBR =number of mosquitoes with a positive midgut and residual tissue/the number of positive midguts $\times 100 \%$

MNBR =number of mosquitoes with a positive midgut but negative residual tissue/the number of positive midguts $\times 100 \%$

\section{Library preparation and RNA sequencing}

Midguts from the $\mathrm{CT}, \mathrm{MB}$ and $\mathrm{MNB}$ groups at each temperature $\left(23^{\circ} \mathrm{C}, 28^{\circ} \mathrm{C}\right.$ and $\left.32^{\circ} \mathrm{C}\right)$ were selected and divided into 9 groups according to the results of the above experiment. The quality and integrity of a single midgut were tested using a 2100 bioanalyzer (Agilent, Santa Clara, USA); midgut RNA concentrations were detected using a Nanodrop 2000. Three midgut samples in each group were mixed as a "pool", where each group had 3 biologically repeated "pools". In total, 27 pools were sent to Wuhan Huada Medical Laboratory for RNA sequencing. Total RNA was purified with the mRNA enrichment method or rRNA removal method, and a cDNA library was constructed. The prepared libraries were sequenced with DNASeqPE150 from BGI (China).

\section{RNA sequence analysis in response to temperature and DENV-2 exposure}

The raw data obtained by RNA sequencing were filtered to remove low-quality data, contaminating linkers, and a high $\mathrm{N}$ content of unknown bases. The filtered data, as clean reads, were compared with the genome of the Foshan strain of Ae. albopictus (AaloF1, VectorBase, https://www. vectorbase.org), and novel transcripts were analyzed. Principal component analysis (PCA) was used to evaluate the sample repeatability and overall differences between samples. The gene length and total reads were normalized. Relative expression levels were assessed as fragments per kilobase of transcript per million fragments mapped (FPKM). Intragroup and intergroup Pearson correlation coefficients were calculated according to FPKM values, and a heatmap was drawn.

\section{Identification of differentially expressed genes and co- expression network modules}

In the R (version 4.0.5) environment, Ballgown package version 2.16.0 was used to analyze the differentially expressed genes (DEGs)[22]. The DEGs of MB and MNB at each temperature and those between two adjacent temperatures in MB or MNB are illustrated by a Venn diagram. DEGs were identified as genes with 2-fold or more changes between samples and a false discovery rate (FDR) $<0.05$. The genes were also analyzed using WGCNA packages[23]. Genes were clustered and divided into different modules; the correlation between the module and the temperature was analyzed, and the module with the highest correlation with temperature was determined. A topological overlap matrix (TOM) was employed to visualize the network of the most relevant modular genes. The R package 
ClusterProfiler version 3.12.0 was applied for gene Ontology (GO) and Kyoto Encyclopedia of Genes and Genomes (KEGG) pathway enrichment analyses[24].

\section{Quantitative real-time PCR (qRT-PCR)}

The genes regulated by temperature were validated by qRT-PCR. The levels of 18 genes were detected in the midguts at different temperatures. RNA and cDNA were synthesized using the above-described protocol. qRT-PCR was performed in triplicate for each sample with SYBR Green Mix (Yeasen, Shanghai, China). The gene expression was normalized to rpS7. The primer sequences are listed in Additional file 2: Table S1. The program was $95^{\circ} \mathrm{C}$ for $5 \mathrm{~min}$, followed by 40 cycles of $95^{\circ} \mathrm{C}$ for $10 \mathrm{~s}, 60^{\circ} \mathrm{C}$ for $10 \mathrm{~s}$ and $72^{\circ} \mathrm{C}$ for $10 \mathrm{~s}$.

\section{Data analysis}

All statistical analyses were performed with SPSS 20.0 (IBM, Chicago, IL, USA). MIR, MBR, and MNBR for Ae. albopictus infected with DENV-2 were separately compared at different temperatures using chi-square (and Fisher's exact) tests. $P$ values were corrected by Bonferroni adjustment. The expression levels of genes were analyzed using Kruskal-Wallis $\mathrm{H}$ test. $P<0.05$ was considered statistically significant.

\section{Results}

Temperature affects the DENV-2 infection and midgut breakthrough in Ae. albopictus.

The DENV-2 virus titer (log10) determined by $\mathrm{TCID}_{50}$ was 8.625. In total, 466 of Ae. albopictus mosquitoes that ingested blood meals containing DENV-2 were used to analyze the midgut infection and breakthrough rates at $23^{\circ} \mathrm{C}, 28^{\circ} \mathrm{C}$ and $32^{\circ} \mathrm{C}$. The MIR was significantly higher at $28^{\circ} \mathrm{C}$ and $32^{\circ} \mathrm{C}$ than at $23^{\circ} \mathrm{C}(P<0.01, P<0.001)$ (Fig. 1A). Although the MIR was higher at $32^{\circ} \mathrm{C}$ than at $28^{\circ} \mathrm{C}$, there was no significant difference between the two groups ( $P=0.107)$ (Fig. 1A). The MBR of Ae. albopictus infected by DENV-2 was closely related to temperature and gradually increased when the temperature increased, although MNBR gradually decreased. The MBR was significantly higher at $28^{\circ} \mathrm{C}$ and $32^{\circ} \mathrm{C}$ than at $23^{\circ} \mathrm{C}$ $(P<0.01, P<0.001)$, whereas the MNBR had the opposite trend (Fig. 1B). The MNBR was significantly higher than the MBR at $23^{\circ} \mathrm{C}$, but the MBR was significantly higher than the MNBR at $28^{\circ} \mathrm{C}$ and $32^{\circ} \mathrm{C}$ (Fig. 1B). These results indicate that the DENV-2 infection and midgut breakthrough in Ae. albopictus are affected by temperature.

Characterization of Ae. albopictus transcriptomes at different temperatures.

Transcriptome sequencing was performed on 27 samples from the CT, MB, and MNB groups at different temperatures $\left(23^{\circ} \mathrm{C}, 28^{\circ} \mathrm{C}\right.$ and $\left.32^{\circ} \mathrm{C}\right)$. Clean reads were obtained after removing low-quality data, and trimmed reads were obtained. Nearly $80 \%$ of the reads were mapped to the Ae. albopictus Foshan strain genome (Table 1). 
Table 1

Overview of the mapping of RNA-seq reads

\begin{tabular}{|c|c|c|c|c|c|}
\hline $\begin{array}{l}\text { Sample } \\
\text { name }\end{array}$ & $\begin{array}{l}\text { Accession } \\
\text { Number }\end{array}$ & $\begin{array}{l}\text { Total } \\
\text { reads }\end{array}$ & $\begin{array}{l}\text { Trimmed Reads in } \\
\text { Pairs }\end{array}$ & $\begin{array}{l}\text { Mapped Trimmed } \\
\text { Reads } \\
\text { to the Genome }\end{array}$ & $\begin{array}{l}\text { Mapping } \\
\text { Rate(\%) }\end{array}$ \\
\hline СT23-1 & SRR16503765 & 54772829 & 43027438 & 44830001 & 81.85 \\
\hline СТ23-2 & SRR16503764 & 53395633 & 42115248 & 43759069 & 81.95 \\
\hline СТ23-3 & SRR16503753 & 54865514 & 43008208 & 45189103 & 82.36 \\
\hline СТ28-1 & SRR16503745 & 55807603 & 42799344 & 45686153 & 81.86 \\
\hline СТ28-2 & SRR16503744 & 54595956 & 42754238 & 44446199 & 81.41 \\
\hline СТ28-3 & SRR16503743 & 55657054 & 43167914 & 45847667 & 82.38 \\
\hline СТ32-1 & SRR16503742 & 54596339 & 43143450 & 44902572 & 82.24 \\
\hline СТ32-2 & SRR16503741 & 54575842 & 43233636 & 44911335 & 82.29 \\
\hline СТ32-3 & SRR16503740 & 53828160 & 43116042 & 44519031 & 82.71 \\
\hline MB23-1 & SRR16503739 & 55680172 & 43272084 & 45751800 & 82.17 \\
\hline MB23-2 & SRR16503763 & 55593162 & 43166298 & 46254004 & 83.20 \\
\hline MB23-3 & SRR16503762 & 53854014 & 43234376 & 43751782 & 81.24 \\
\hline MB28-1 & SRR16503761 & 54532721 & 42916424 & 44240737 & 81.13 \\
\hline MB28-2 & SRR16503760 & 55082520 & 43313808 & 45303233 & 82.25 \\
\hline MB28-3 & SRR16503759 & 53442771 & 42876264 & 43282494 & 80.99 \\
\hline MB32-1 & SRR16503758 & 54496832 & 43216764 & 44790010 & 82.19 \\
\hline MB32-2 & SRR16503757 & 54009938 & 43101818 & 44081104 & 81.62 \\
\hline MB32-3 & SRR16503756 & 53385010 & 42789656 & 43476908 & 81.44 \\
\hline $\begin{array}{l}\text { MNB23- } \\
1\end{array}$ & SRR16503755 & 55517642 & 42595030 & 46663792 & 84.05 \\
\hline $\begin{array}{l}\text { MNB23- } \\
2\end{array}$ & SRR16503754 & 54594901 & 42346994 & 44982402 & 82.39 \\
\hline $\begin{array}{l}\text { MNB23- } \\
3\end{array}$ & SRR16503752 & 55500160 & 42492630 & 46458788 & 83.71 \\
\hline $\begin{array}{l}\text { MNB28- } \\
1\end{array}$ & SRR16503751 & 56410592 & 43144664 & 47226360 & 83.72 \\
\hline $\begin{array}{l}\text { MNB28- } \\
2\end{array}$ & SRR16503750 & 54893018 & 43252930 & 45876636 & 83.57 \\
\hline
\end{tabular}




\begin{tabular}{|llllll|}
\hline $\begin{array}{l}\text { Sample } \\
\text { name }\end{array}$ & $\begin{array}{l}\text { Accession } \\
\text { Number }\end{array}$ & $\begin{array}{l}\text { Total } \\
\text { reads }\end{array}$ & $\begin{array}{l}\text { Trimmed Reads in } \\
\text { Pairs }\end{array}$ & $\begin{array}{l}\text { Mapped Trimmed } \\
\text { Reads } \\
\text { to the Genome }\end{array}$ & $\begin{array}{l}\text { Mapping } \\
\text { Rate(\%) }\end{array}$ \\
\hline $\begin{array}{l}\text { MNB28- } \\
3\end{array}$ & SRR16503749 & 54651677 & 42863124 & 45496019 & 83.25 \\
\hline $\begin{array}{l}\text { MNB32- } \\
1\end{array}$ & SRR16503748 & 55653684 & 43066758 & 45287828 & 81.37 \\
\hline $\begin{array}{l}\text { MNB32- } \\
2\end{array}$ & SRR16503747 & 53792991 & 42047606 & 45040839 & 83.73 \\
\hline $\begin{array}{l}\text { MNB32- } \\
3\end{array}$ & SRR16503746 & 53760318 & 43236118 & 43159101 & 80.28 \\
\hline
\end{tabular}

PCA was used to analyze the variance of in-group samples and gene expression patterns associated with temperature, infection and breakthrough of the midgut. The PCA plot showed a high degree of reproducibility among replicate samples (Fig. 2A), and gene expression datasets of midguts clustered at different temperatures (Fig. 2B). Overall, the expression profiles of midgut transcripts changed in response to blood feeding between the control group and the infection group (Fig. 2C), and the clustering of transcript profiles was affected by midgut breakthrough (Fig. 2D). Furthermore, we analyzed Pearson correlation coefficients among all samples, and a heatmap showed correlation values of paired samples between 0.75 and 1 (Additional file 1: Figure S1).

Temperature alters Ae. albopictus transcriptomes during DENV-2 infection.

DEGs between CT and MB were analyzed at each temperature. There were $469 \mathrm{DEGs}$ at $23^{\circ} \mathrm{C}, 139$ at $28^{\circ} \mathrm{C}$ and 156 at $32^{\circ} \mathrm{C}$, which included 3 upregulated and 10 downregulated genes at two temperatures (Fig. 3A). Compared to DEGs between CT and MB, the transcriptomes between CT and MNB were altered, with 180 DEGs at $23^{\circ} \mathrm{C}, 90$ at $28^{\circ} \mathrm{C}$ and 140 at $32^{\circ} \mathrm{C}$, which included 3 upregulated genes and 4 downregulated genes at two temperatures (Fig. 3B). Since temperature is an important factor that affected the midgut barrier, we analyzed MB and MNB DEGs at different temperatures. Most DEGs were observed at $23^{\circ} \mathrm{C}$, followed by $28^{\circ} \mathrm{C}$, with the smallest number at $32^{\circ} \mathrm{C}$. There were no overlapping genes among the groups (Fig. 3C). The data show that the Ae. albopictus midgut transcriptomes change in response to temperature.

In addition, DEGs were different between MB and MNB compared to CT at the same temperature. At $23^{\circ} \mathrm{C}$, 231 upregulated and 241 downregulated genes sharply changed between CT and MB, which was far more than those between CT and MNB (Fig. 3D). At $28^{\circ} \mathrm{C}$, the numbers of DEGs between CT and MB were almost identical to those between $\mathrm{CT}$ and MNB (Fig. $3 \mathrm{E}$ ). At $32^{\circ} \mathrm{C}$, there were 45 upregulated and 82 downregulated genes between $\mathrm{CT}$ and $\mathrm{MB}$ and 33 upregulated and 46 downregulated genes between $\mathrm{CT}$ and MNB (Fig. 3F). These results demonstrate that the Ae. albopictus midgut transcriptome is affected by the midgut barrier. 


\section{Key gene network associated with the DENV-2 infection identified by WGCNA.}

To construct a WGCNA network, we first calculated the thresholding power to perform network topology analysis. The thresholding power was set at 4 in WGCNA because the scale independence reached 0.9 and presented suitable mean connectivity (Fig. 4A). Modules were determined using the WGCNA R package. The hierarchical cluster tree showed 28 modules of co-expressed genes (Fig. 4B), and the eigengene adjacency heatmap indicated a relationship between pairwise gene modules (Fig. 4C). Correlations between modules and temperature and ingestion DENV-2 blood meal were analyzed by WGCNA. According to the results, the ME3 module had the highest correlation with temperature, and the ME12 module was highly associated with the ingestion of a viral blood meal (Fig. 4D).

\section{Functional analysis of the key module associated with temperature.}

In this study, we focused on the pathway by which temperature affected the transmission of DENV-2 by Ae. albopictus. The ME3 module correlated with temperature was evaluated by GO and KEGG analyses. Unfortunately, no significant GO terms were enriched in this module (Additional file 1: Figure S2). In the KEGG analysis, RNA degradation, Toll and IMD signaling pathways and other pathways were enriched. Hence, these pathways are regulated by temperature (Fig. 5A). The genes involved in RNA degradation, Toll and IMD signaling pathways, nitrogen metabolism, fatty acid degradation and riboflavin metabolism are listed in Table 2 (Fig. 5B). 
Table 2

Module genes regulated by temperature

\begin{tabular}{|c|c|c|}
\hline $\begin{array}{l}\text { Module-regulated } \\
\text { pathway }\end{array}$ & $\begin{array}{l}\text { Gene } \\
\text { number }\end{array}$ & Protein \\
\hline \multirow[t]{5}{*}{ RNA degradation } & 109401683 & m7GpppN-mRNA hydrolase \\
\hline & 109420650 & U6 snRNA-associated Sm-like protein LSm4 \\
\hline & 109399943 & CCR4-NOT transcription complex subunit 6-like \\
\hline & 109418111 & protein PAT1 homolog 1 \\
\hline & 109401240 & heat shock $70-k D a$ protein cognate 5 \\
\hline \multirow[t]{5}{*}{ Toll and Imd pathway } & 109404401 & modular serine protease-like \\
\hline & 115262585 & uncharacterized LOC115262585 \\
\hline & 109422736 & peptidoglycan-recognition protein LB-like \\
\hline & 109426919 & uncharacterized LOC109426919 \\
\hline & 115266575 & myeloid differentiation primary response protein MyD88-like \\
\hline \multirow[t]{3}{*}{ Nitrogen metabolism } & 109399946 & glutamine synthetase 2 cytoplasmic \\
\hline & 115256594 & carbonic anhydrase 1-like \\
\hline & 109419671 & carbonic anhydrase 1-like \\
\hline \multirow[t]{3}{*}{ Fatty acid degradation } & 109400327 & $\begin{array}{l}\text { very long-chain specific acyl-CoA dehydrogenase, } \\
\text { mitochondrial-like }\end{array}$ \\
\hline & 109416406 & acetyl-CoA acetyltransferase, cytosolic-like \\
\hline & 109407255 & carnitine 0-palmitoyltransferase 2 , mitochondrial-like \\
\hline \multirow[t]{2}{*}{ Riboflavin metabolism } & 115255392 & testicular acid phosphatase \\
\hline & 109405306 & flavin reductase (NADPH) \\
\hline
\end{tabular}

\section{Validation of hub genes regulated by temperature}

According to references, we selected eight genes related to the antiviral immunity of mosquitoes for validation. The expression levels of these genes were analyzed from RNA-seq datasets (Fig. 6) and detected by qRT-PCR (Fig. 7). The expression trends of most samples showed similar results between RNA-seq and qRT-PCR. Kruskal-Wallis H test demonstrated that "LOC109399943" annotated as "CCR4NOT transcription complex subunit 6-like", "LOC109418111" annotated as "protein PAT1 homolog 1" and "LOC109401240" annotated as "heat shock 70-kDa protein cognate 5" were significantly different in the overall samples. These hub genes regulated by temperature will provide targets for dengue prevention. 


\section{Discussion}

Model predictions and laboratory studies have shown that temperature affects the vector competence of Ae. albopictus for transmitting DENV $[16,25]$. However, little is known about the underlying mechanisms. In this study, RNA sequencing of the midguts of Ae. albopictus in the CT, MB and MNB groups was conducted, and the results reveal different transcriptional variations in response to DENV infection and temperature. WGCNA was used to identify key gene networks regulated by temperature. Then, we determined hub pathways associated with temperature.

In this research, we collected Ae. albopictus mosquitoes with different infection statuses. To simultaneously collect mosquitoes with and without midgut breakthrough at $23^{\circ} \mathrm{C}, 28^{\circ} \mathrm{C}$ and $32^{\circ} \mathrm{C}$, we determined the optical concentration of DENV-2 to be $8.625 \log 10 \mathrm{TCID}_{50} / \mathrm{mL}$ based on preliminary experimental results, with a time to harvest of 7 days after infection. Under this condition, the MIR, MBR and MNBR of Ae. albopictus were detected. The trend of the results was consistent with previous experimental research and model predictions $[16,25,26]$.

The transcriptome of the midgut of Aedes mosquitoes is altered by the DENV infection. Indeed, expression profiles of the Ae. aegypti midgut responding to DENV infection were changed. For example, antimicrobial peptides (AMPs) induced by the Toll immune pathway reportedly increased at 7 days postinfection [27], and Ae. albopictus midgut genes were modulated by DENV exposure in a time- and sitespecific manner [28]. In our study, the expression profiles of the Ae. albopictus midgut clustered after the ingestion of a blood meal containing DENV-2. Furthermore, we analyzed Ae. albopictus transcriptomes of the MB and MNB groups at different temperatures and found that temperature affected the midgut transcriptome clustering: low temperature resulted in more DEGs. Similar to our findings, previous research has demonstrated that temperature shapes Ae. aegypti gene expression after ZIKV infection [19].

To better understand the relationship between temperature and infection in Ae. albopictus, we used WGCNA, which is a method for gene co-expression networks $[29,30]$. In 2008, the WGCNA software package was developed using $R$; it is mainly used to analyze large sample expression data, such as gene expression microarray or RNA sequencing data [23]. WGCNA has been proven to be an effective method to detect co-expressed modules and hub genes in tumors, plants, parasites, etc [31-33]. In this study, the highest correlation with temperature was observed for the ME3 module.

The mosquito transcriptome changed in response to DENV, which might be related to the mosquito's antiviral system. In contrast to the innate and adaptive immunity of humans to resist the invasion of pathogens, mosquitoes lack adaptive immunity and mainly rely on innate immunity to suppress virus proliferation. RNA interference (RNAi), Toll, immunodeficiency factor (IMD), Janus kinase pathway signal transduction and activation (JAK-STAT) and other pathways play an important role in the mosquito antiviral immunity [34]. The gene expression profiles of mosquitoes infected with viruses were transformed following temperature change. In a previous study, Ae. aegypti infected with chikungunya 
virus (CHIKV) were cultured at $18^{\circ} \mathrm{C}, 28^{\circ} \mathrm{C}$ and $32^{\circ} \mathrm{C}$; the Toll, IMD and JAK-STAT pathways were upregulated at $28^{\circ} \mathrm{C}$, and high temperature appeared to damage the immune defenses [35]. In our study, the pathways of the ME3 module regulated by temperature included RNA degradation, Toll pathway and IMD pathway.

DENV is an RNA virus, and the RNA degradation pathway is closely related to the proliferation of DENV in mosquitos [36]. Many eukaryotic proteins that interact with the $5 \mathrm{~m} 7 \mathrm{GpppN}$ cap affect the metabolism

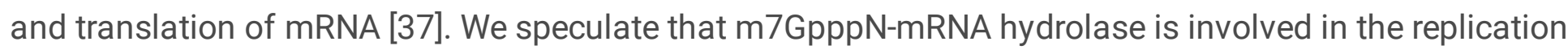
of DENV in Ae. albopictus. Sm-like (Lsm) proteins participate in pre-mRNA splicing, nuclear RNA processing and miRNA biogenesis and mediate the antiviral immunity through the RNAi pathway [38]. PAT1 is an RNA-binding protein that plays a role in mRNA decay by physically linking de-adenylation with de-capping and by acting as a translation repressor to regulate the gene expression [39]. The Lsm1-7Pat1 complex binds to cis-acting regulatory sequences of viral positive-strand RNA genomes, which promotes the transcription, translation and replication of the virus [40]. heat shock cognate 70 protein interacts with CHIKV to promote its entry into $\mathrm{C6} / 36$ cells [41], and 70-kDa heat shock cognate proteins have been identified as the most critical components in DENV-4 binding and entry into C6/36 cells [42]. Additionally, the CCR4-NOT transcription complex subunit 6-like belongs to the CCR4-NOT complex family, which is involved in the transcription, translation and mRNA decay [43]. The expression level of CCR4-Not complex genes was up-regulated in DENV-infected cells, which is conducive to the proliferation of DENV [44]. In this study, it was highly expressed at $32^{\circ} \mathrm{C}$, which suggests that DENV-2 proliferated more quickly at $32^{\circ} \mathrm{C}$, which helped DENV-2 break through the midgut barrier.

Regarding Toll pathways, pattern recognition receptors (PRRs) recognize mosquito-borne viruses, which promotes the maturation of Spätzle (Spz). The Spz interaction with Toll-like receptors (TLRs) involves myeloid differentiation gene 88 (MyD88), followed by the activation of the nuclear transcription factor (NF-KB), which induces the release of nuclear antimicrobial peptides (AMPs) and other antiviral molecules [45]. Three proteins are regulated by temperature: modular serine protease, peptidoglycanrecognition protein (PGRP) and MyD88. Modular serine protease is recruited to the lysine-type peptidoglycan recognition complex, which activates the serine protease cascade [46]. It serves as a crucial enzyme to elicit insect immune responses, especially for Toll pathway activation [47]. PGRP is the most important PRR in insects; it can bind to and hydrolyze bacterial peptidoglycan to activate innate immunity $[48,49]$. MyD88 serves as the key mediator of Toll signaling. The inhibition of MyD88 significantly enhances the replication of DENV-2 in Ae. Aegypti [50]. MyD88 is also involved in the antiviral immunity of Ae. aegypti against Japanese encephalitis virus (JEV) [51].

In this study, functional verification of these genes regulated by temperature was absent. We will design the siRNA and dsRNA of these genes to detect the proliferation ability of DENV-2 at the cell level and analyze the vector competence of Ae. albopictus to transmit DENV-2 at different temperatures.

\section{Conclusion}


To explore the mechanism by which temperature affects the transmission of DENV-2 by Ae. albopictus, we examined variational transcriptomes of Ae. albopictus midguts at different temperatures using RNA sequencing. The altered genes identified may be involved in virus resistance or viral infection, and $A e$. albopictus may be more susceptible to DENV-2 when these genes are altered. Some important pathways, including the RNA degradation, Toll and IMD pathways, were identified by WGCNA and KEGG analysis as being regulated by temperature. This study provides experimental evidence to prevent and control dengue.

\section{Abbreviations}

DENV

dengue virus

CT

The control group

$\mathrm{MB}$

The midgut breakthrough group

MNB

The midgut nonbreakthrough group

MIR

Midgut infection rate

MBR

Midgut breakthrough rate

MNBR

Midgut nonbreakthrough rate

DEGs

Differentially expressed genes

WGCNA

Weighted gene correlation network analysis

PCA

Principal component analysis

$\mathrm{TCID}_{50}$

$50 \%$ tissue culture infective dose

GO

Gene ontology

KEGG

Kyoto encyclopedia of genes and genomes

qRT-PCR

Quantitative real-time PCR.

\section{Declarations}


Acknowledgements

Not applicable.

\section{Authors' contributions}

$Z Z L$ and $Y X$ designed the study. ZZL wrote the manuscript. ZZL and YDL collected the mosquito samples. $Y X, S H X, Y J L$ and $C H$ analyzed the data. $L X, X G C$ and $K Y Z$ contributed reagents and revised the initial manuscript draft. All authors approved the final manuscript.

\section{Funding}

This work was supported by grants from the National Natural Science Foundation of China (No. 82002157,82060379 and 81660345), Natural Science Foundation of Jiangsu of China (No. BK20180994), Fund for Postdoctoral Research in China (No. 2018M632382), and Hainan Natural Science Foundation (820RC653).

\section{Availability of data and materials}

Publicly available datasets were analyzed in this study. Sequencing data were deposited at the NCBI Sequence Read Archive (SRA) under the accession number SRP342340.

\section{Ethics approval and consent to participate}

Not applicable.

\section{Consent for publication}

Not applicable.

\section{Competing interests}

The authors declare that they have no competing interests.

\section{References}

1. Hamer DH. Dengue-Perils and Prevention. N Engl J Med. 2021;384:2252-3.

2. Wilder-Smith A, Ooi EE, Horstick O, Wills B. Dengue Lancet. 2019;393:350-63.

3. Bhatt S, Gething PW, Brady OJ, Messina JP, Farlow AW, Moyes CL, et al. The global distribution and burden of dengue. Nature. 2013;496:504-7.

4. Dos ST, Martin J, Castellanos LG, Espinal MA. Dengue in the Americas: Honduras' worst outbreak. Lancet. 2019;394:2149. 
5. Wilder-Smith A, Rupali P. Estimating the dengue burden in India. Lancet Glob Health. 2019;7:e988-9.

6. Cousins S. Dengue rises in Bangladesh. Lancet Infect Dis. 2019;19:138.

7. The L. 2020: a crucial year for neglected tropical diseases. Lancet. 2019;394:2126.

8. Chen B, Liu Q. Dengue fever in China. Lancet. 2015;385:1621-2.

9. Zhao H, Zhang FC, Zhu Q, Wang J, Hong WX, Zhao LZ, et al. Epidemiological and Virological Characterizations of the 2014 Dengue Outbreak in Guangzhou, China. PloS One. 2016;11:e156548.

10. Guzman MG, Gubler DJ, Izquierdo A, Martinez E, Halstead SB. Dengue infection. Nat Rev Dis Primers. 2016;2:16055.

11. Liu B, Gao X, Ma J, Jiao Z, Xiao J, Hayat MA, et al. Modeling the present and future distribution of arbovirus vectors Aedes aegypti and Aedes albopictus under climate change scenarios in Mainland China. Sci Total Environ. 2019;664:203-14.

12. Franklinos $L$, Jones KE, Redding DW, Abubakar I. The effect of global change on mosquito-borne disease. Lancet Infect Dis. 2019;19:e302-12.

13. Friedrich MJ. Global Temperature Affects Dengue. JAMA. 2018;320:227.

14. Colon-Gonzalez FJ, Harris I, Osborn TJ, Steiner SBC, Peres CA, Hunter PR, et al. Limiting global-mean temperature increase to $1.5-2^{\circ} \mathrm{C}$ could reduce the incidence and spatial spread of dengue fever in Latin America. Proc Natl Acad Sci USA. 2018;115:6243-8.

15. Carrington LB, Armijos MV, Lambrechts L, Scott TW. Fluctuations at a low mean temperature accelerate dengue virus transmission by Aedes aegypti. PLoS Negl Trop Dis. 2013;7:e2190.

16. Liu Z, Zhang Z, Lai Z, Zhou T, Jia Z, Gu J, et al. Temperature Increase Enhances Aedes albopictus Competence to Transmit Dengue Virus. Front Microbiol. 2017;8:2337.

17. Franz AW, Kantor AM, Passarelli AL, Clem RJ. Tissue Barriers to Arbovirus Infection in Mosquitoes. Viruses. 2015;7:3741-67.

18. Kumar A, Srivastava P, Sirisena P, Dubey SK, Kumar R, Shrinet J, et al. Mosquito Innate Immunity. Insects. 2018;9.

19. Ferreira PG, Tesla B, Horacio E, Nahum LA, Brindley MA, de Oliveira MT, et al. Temperature Dramatically Shapes Mosquito Gene Expression With Consequences for Mosquito-Zika Virus Interactions. Front Microbiol. 2020;11:901.

20. Ramakrishnan MA. Determination of $50 \%$ endpoint titer using a simple formula. World J Virol. 2016;5:85-6.

21. Lanciotti RS, Calisher CH, Gubler DJ, Chang GJ, Vorndam AV. Rapid detection and typing of dengue viruses from clinical samples by using reverse transcriptase-polymerase chain reaction. $\mathrm{J}$ Clin Microbiol. 1992;30:545-51.

22. Frazee AC, Pertea G, Jaffe AE, Langmead B, Salzberg SL, Leek JT. Ballgown bridges the gap between transcriptome assembly and expression analysis. Nat Biotechnol. 2015;33:243-6.

23. Langfelder $P$, Horvath S. WGCNA: an R package for weighted correlation network analysis. BMC Bioinformatics. 2008;9:559. 
24. Yu G, Wang LG, Han Y, He QY. clusterProfiler: an R package for comparing biological themes among gene clusters. OMICS. 2012;16:284-7.

25. Xu L, Stige LC, Chan KS, Zhou J, Yang J, Sang S, et al. Climate variation drives dengue dynamics. Proc Natl Acad Sci USA. 2017;114:113-8.

26. Huber JH, Childs ML, Caldwell JM, Mordecai EA. Seasonal temperature variation influences climate suitability for dengue, chikungunya, and Zika transmission. PLoS Negl Trop Dis. 2018;12:e6451.

27. Wang JM, Cheng Y, Shi ZK, Li XF, Xing LS, Jiang H, et al. Aedes aegypti HPX8C modulates immune responses against viral infection. PLoS Negl Trop Dis. 2019;13:e7287.

28. Tsujimoto H, Hanley KA, Sundararajan A, Devitt NP, Schilkey FD, Hansen IA. Dengue virus serotype 2 infection alters midgut and carcass gene expression in the Asian tiger mosquito, Aedes albopictus. PloS One. 2017;12:e171345.

29. Stuart JM, Segal E, Koller D, Kim SK. A gene-coexpression network for global discovery of conserved genetic modules. Science. 2003;302:249-55.

30. Zhang B, Horvath S. A general framework for weighted gene co-expression network analysis. Stat Appl Genet Mol Biol. 2005;4:e17.

31. Jia R, Zhao H, Jia M. Identification of co-expression modules and potential biomarkers of breast cancer by WGCNA. Gene. 2020;750:144757.

32. Feng X, Zhu L, Qin Z, Mo X, Hao Y, Jiang Y, et al. Temporal transcriptome change of Oncomelania hupensis revealed by Schistosoma japonicum invasion. Cell Biosci. 2020;10:58.

\section{Figures}

a

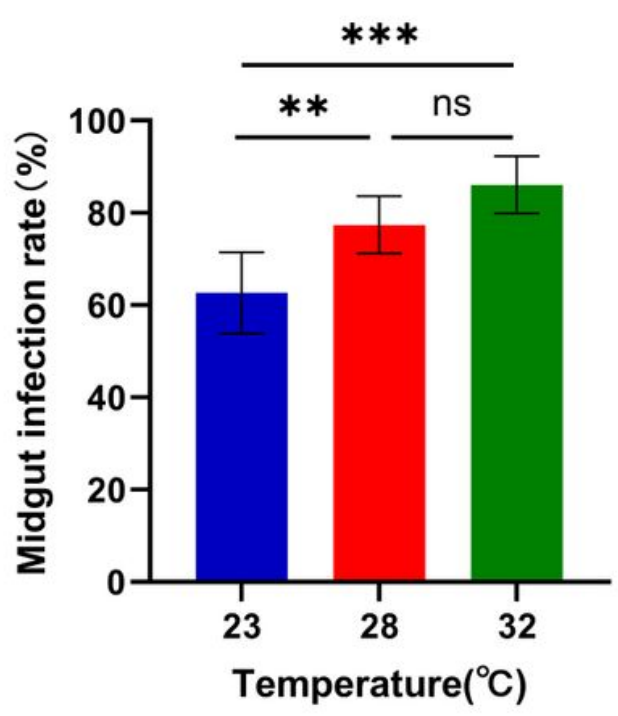

b

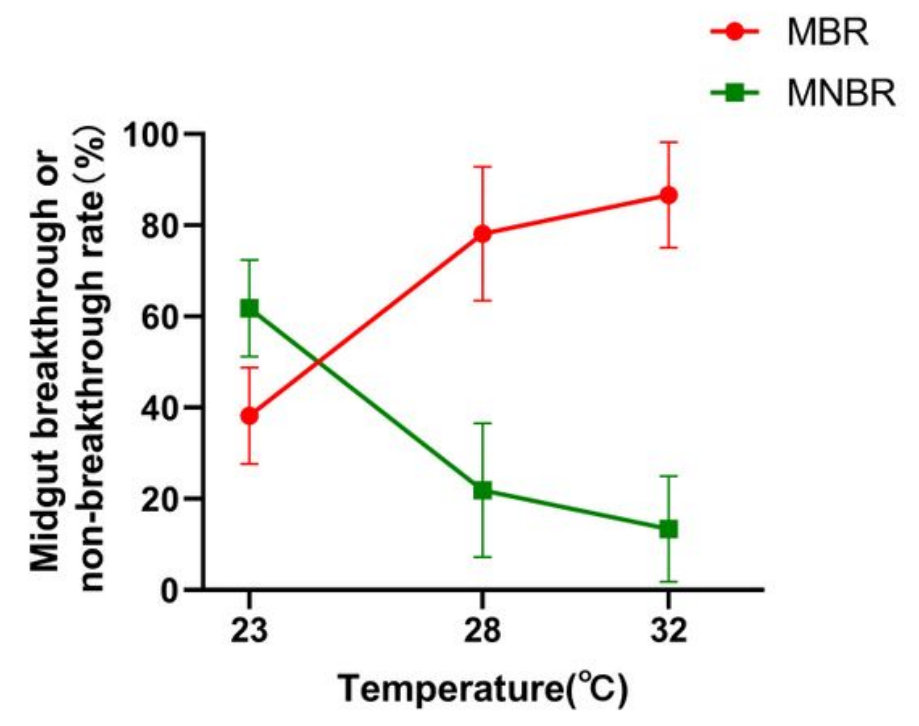

Figure 1 
Analysis of the midgut of Ae. albopictus infected with DENV-2 at different temperatures. Ae. albopictus orally infected with DENV-2 were reared at $23^{\circ} \mathrm{C}, 28^{\circ} \mathrm{C}$ and $32^{\circ} \mathrm{C}$. The midguts and residual tissue were dissected at $7 \mathrm{~d}$, and DENV-2 was detected by PCR. (a) Midgut infection rate (MIR). (b) Analysis of midgut breakthrough in Ae. albopictus at different temperatures. The error bars represent the $95 \%$ confidence interval (Cl).
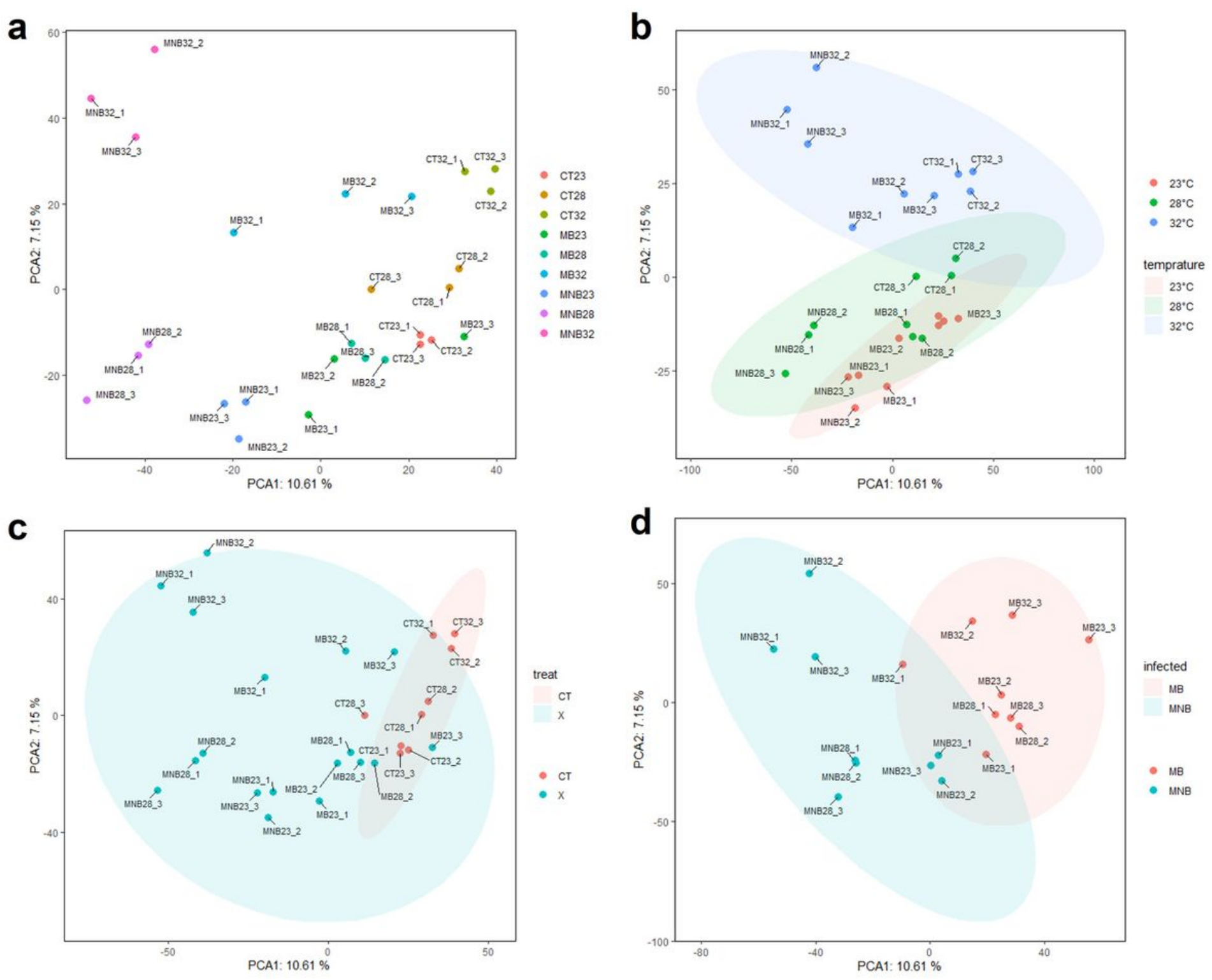

Figure 2

PCA of the general transcriptome characteristics of Ae. albopictus. PCA1 and PCA2 accounted for $10.61 \%$ and $7.15 \%$ of the total variance in the dataset, respectively. Cluster analysis of transcriptome data from a single sample(a), samples at different temperatures (b), midgut datasets associated with viral treatment(c) and midgut breakthrough status(d). 
a
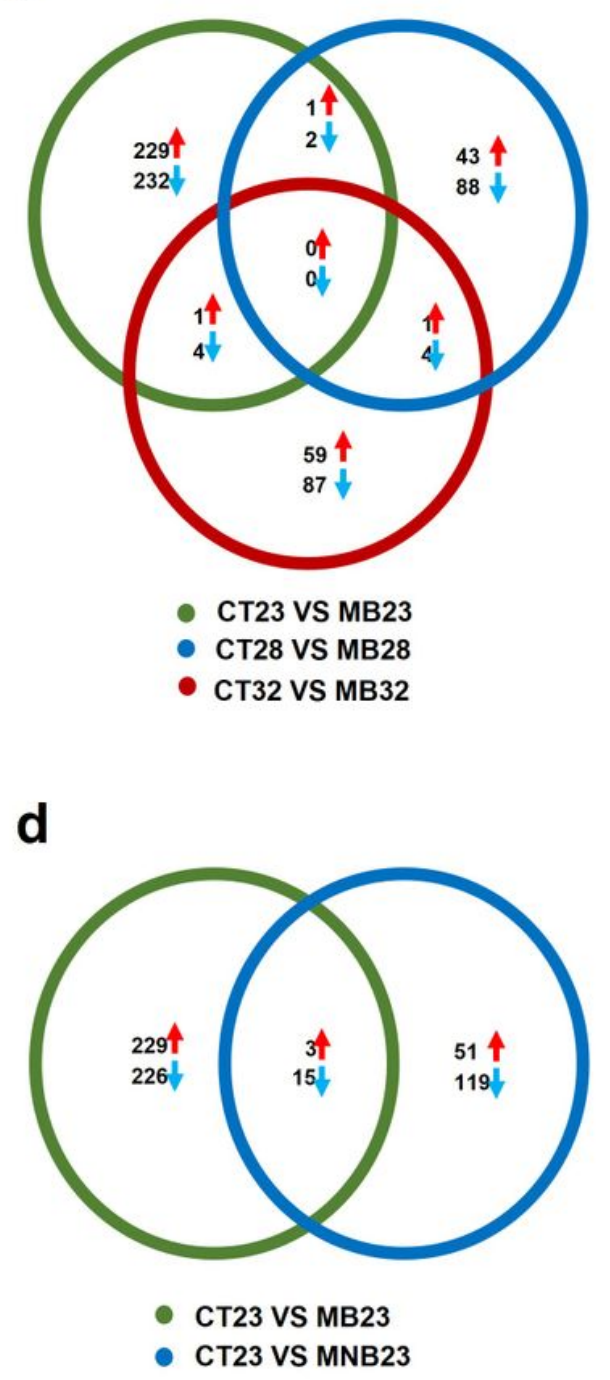

b

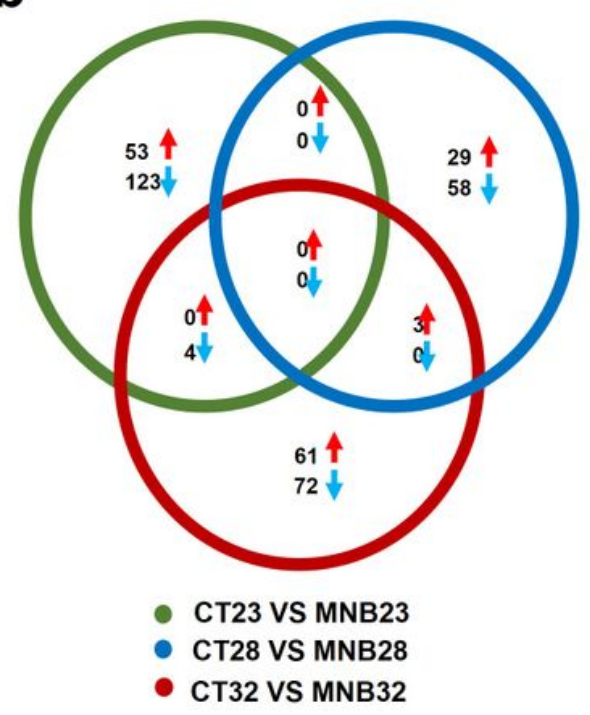

e

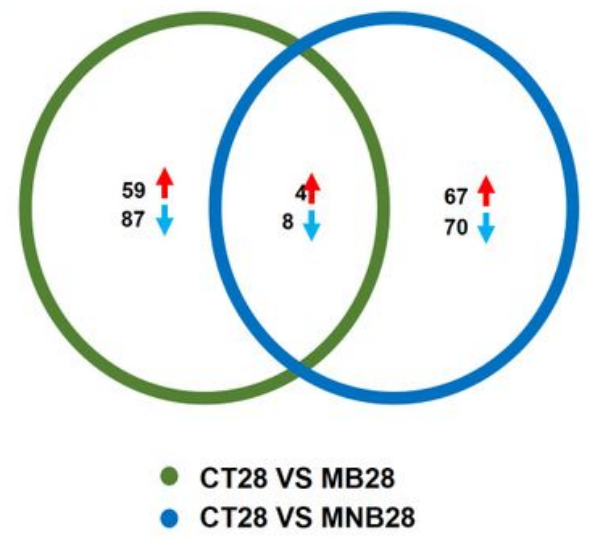

C

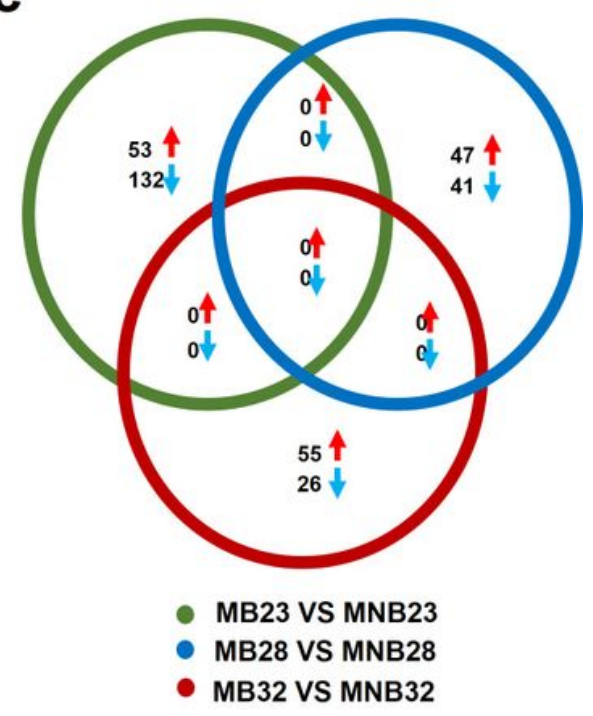

f

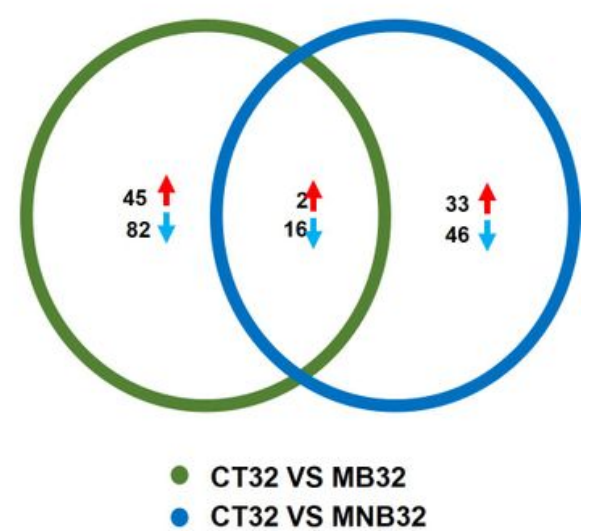

Figure 3

Venn diagram representation of the number of DEGs identified by the RNA-seq analysis in the midguts of Ae. albopictus. Number of DEGs between CT and MB(a), CT and MNB(b), MB and MNB(c) at different temperatures; (d) MB and MNB compared to $C T$ at $23^{\circ} \mathrm{C}$; (e) MB and MNB compared to $C T$ at $28^{\circ} \mathrm{C}$; (f) MB and MNB compared to $\mathrm{CT}$ at $32^{\circ} \mathrm{C}$.

\section{Figure 4}

WGCNA revealed gene co-expression networks. (a) Analysis of network topology for various softthresholding powers. (b) The hierarchical cluster tree shows 28 modules of co-expressed genes. (c) The eigengene adjacency heatmap indicates the relationship between the pairwise gene modules. (d) Correlations between modules and temperature. Each unit contains the weight correlation coefficients and $P$ values. 
a

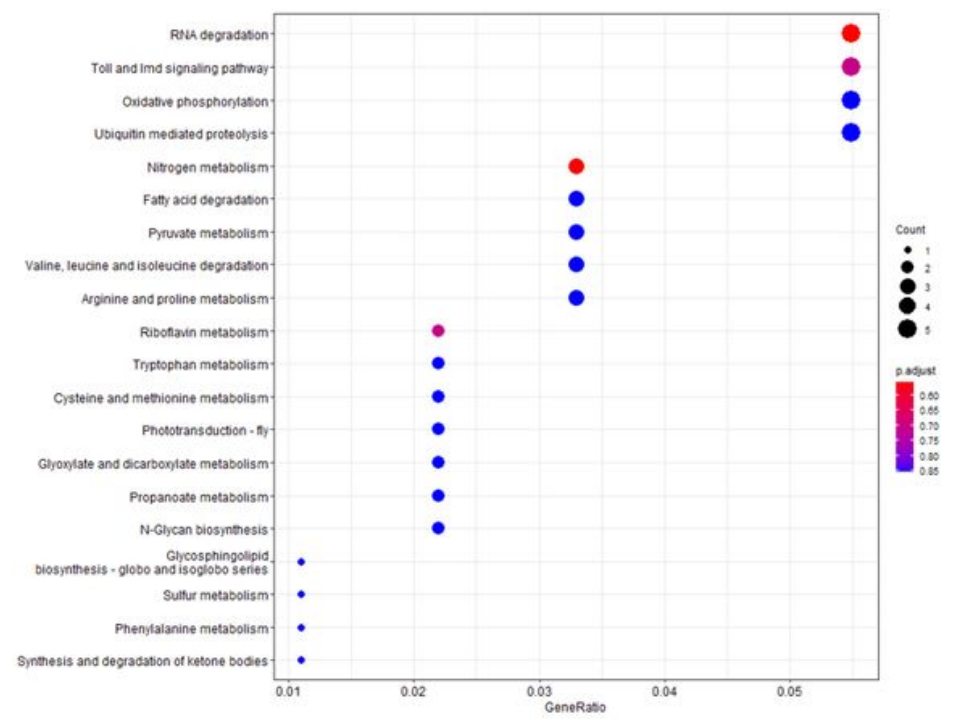

b

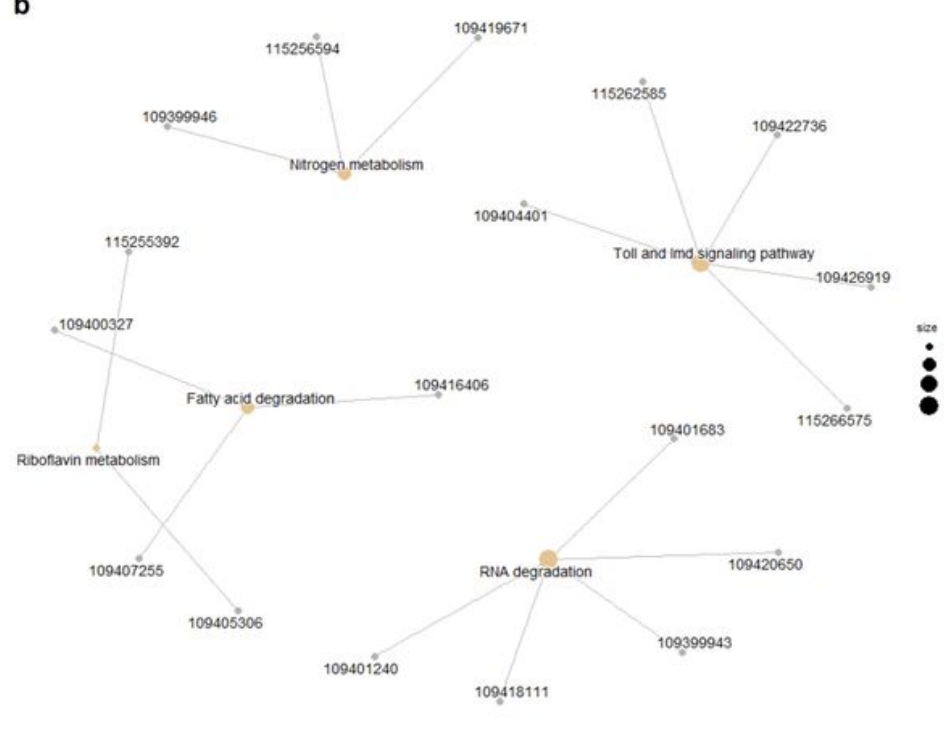

Figure 5

Functional analysis of the key module associated with temperature. (a) KEGG enrichment analysis of DEGs from the ME3 module. (b) Genes corresponding to the partial pathway regulated by temperature.

Figure 6

Analysis of the expression of hub genes regulated by temperature by RNA-seq.

Figure 7

Validation of the expression of hub genes regulated by temperature by qRT-PCR.

\section{Supplementary Files}

This is a list of supplementary files associated with this preprint. Click to download.

- abstract.jpg

- figS1.jpg

- figS2.jpg

- TableS1.xIsx 